\title{
Investigating the Mediation and Moderation Effect of Students' Addiction to Virtual Reality Games: A Perspective of Structural Equation Modeling
}

\author{
Xuesong Zhai, ${ }^{1}$ Fahad Asmi, ${ }^{2}$ Rongting Zhou, ${ }^{2}$ Intikhab Ahmad ${ }^{1}{ }^{2}$ \\ Muhammad Azfar Anwar, ${ }^{2}$ Saba Saneinia, ${ }^{2}$ and Man $\mathrm{Li}^{3}$ \\ ${ }^{1}$ College of Education, Zhejiang University, Hangzhou, China \\ ${ }^{2}$ Department Science and Technology Communication and Policy, University of Science and Technology of China, Hefei, China \\ ${ }^{3}$ Hefei Institute of Adolescent Psychology, Hefei, China
}

Correspondence should be addressed to Intikhab Ahmad; intikhabahmad@mail.ustc.edu.cn

Received 28 July 2020; Revised 23 August 2020; Accepted 4 September 2020; Published 24 September 2020

Academic Editor: Shaohui Wang

Copyright (C) 2020 Xuesong Zhai et al. This is an open access article distributed under the Creative Commons Attribution License, which permits unrestricted use, distribution, and reproduction in any medium, provided the original work is properly cited.

\begin{abstract}
Virtual reality (VR) games construct an immersive context for the youth's entertainment and learning. VR game addiction (VAD) occurs simultaneously and brings about psychological issues. The current research employed a maximum likelihood estimation method to construct a structural equation model, by which learners' VR consumption behaviors were examined. The bootstrapping approach was adopted to explore further the mediation of VR realism (VRR) and the moderation of VR affordance on learners' VAD, which potentially leads to distressing behavioral and psychological circumstances. Data were collected from 575 students recruited in the survey, which was followed by a test of reliability and validity through confirmative factor analysis. Results concluded that VRR and consumers' cognitive satisfaction played a significant role as mediators while conceptualizing addictive behavior based on VR-perceived experience of consumers, self-efficacy, and interactivity. Moreover, this study conceptualized addictive behavior toward VR games through a structural equation model in a media-rich environment and suggested practical implications to reduce addictive behavior.
\end{abstract}

\section{Introduction}

Virtual reality (VR) refers to the gadget that simulates interactive virtual settings in a $3 \mathrm{D}$ image, which offers an immersive environment than another display screen (i.e., desktop, television, or mobile phone). Previous studies have illuminated that VR brought about various benefits in gaming. For example, it provides opportunities to socialize with other players online. Some users prefer to experience various emotions in VR games to satisfy their psychological needs, whereas others aim to pass the time or escape reality for the time being [1]. Students are a dominant group in VR games, and many researchers have begun to investigate the use of VR games in enhancing learners' fulfillment in the educational domain. VR games provide virtual conditions, where people could improve their skills that could be positively used in real life. For example, memory games are used to improve cognitive abilities, and adventure games help people cope with qualms [2].

However, the use of VR games may have a negative influence on learners' relationships with their family, education, and social life and may lead to VAD. To quantify the addictive behavior of VR game users, the current study, which is based on the cognitive-behavioral framework, employed structural equation modeling (SEM) to construct a holistic model that reflects the driving mechanism leading to VAD. The structural equation is a reliable modeling approach to explain the relationship between variables and latent constructs systematically. To evaluate the model fitness and path coefficient of the proposed model, this study employed a maximum likelihood estimation (MLE) to 
estimate the parameters of a probability distribution by maximizing a likelihood function.

\section{Literature Review on VR Addiction}

Information technology (IT) has become an essential part of modern society, and its application ranges from education to entertainment and even health. Life is becoming more manageable with IT; however, research has indicated various severe concerns about this exposure (e.g., IT addiction and stress) [3]. Similarly, some studies on technology addiction have discussed that addictions have different types. Specifically, Internet-addicted users are keen toward porn, gambling, and e-gaming addiction. Some researchers have argued that addiction can also have positive effects [4]. Researchers still disagree on definitions. The American Society for Addiction Medicine defines addiction as a primary, acute illness of brain reward, consciousness, and associated circuitry. Moreover, addiction is defined as the incapacity to abstain constantly, the impairment of cognitive command, and the reduced awareness and dysfunctional reaction to important cognitive issues and interpersonal relations [5]. Addiction is a progressive disability and results in premature death without treatment or rehabilitation. A research review identified the four most frequently studied types of IT addiction, namely, Internet addiction, gambling disorder, smartphone addiction, and social network addiction. These types of IT addiction share some common symptoms but also have some unique features [6].

Studies have discussed that Internet addiction and FBA are interconnected. Facebook is widely used in SNS research. Facebook claimed to have 2414 million active users per month [7]. Moreover, the Pew Research Center's Internet and American Life Program describes technology use as essential to everyday life, particularly for teenagers and adults who use smart phones [8]. College-aged students are more attached to and reliant on smartphones; according to a Pew research survey, 94\% of young people aged 18-24 years have smartphones [9]. Gökçearslan et al. [10] stated that frequently using smartphones is an indication of addiction to smartphones. Smartphone addiction leads to serious health issues for young people. Researchers have further argued that young people have nomophobia, which is the fear of being without smartphones [11]. Similarly, online game addiction (OGA) is considered the most critical issue in public health among other related fields. Game addiction is defined as prolonged gaming that leads to behavioral symptoms, including the loss of self-control. Moreover, Internet gaming disorder (IGD) is now included in DMS-5 and ICD-II, but the addiction debate continues. DSM-5 identified addicts of digital games as "gamers" who compulsively play Internet games and exclude other activities, which may lead to psychosocial impairment or stress. Previous studies have used the time spent playing as a gaming disorder indicator, but research still needs to determine whether both are the same or considered similar [12]. Studies have identified that adolescents who are addicted to games have a negative relationship with their parents, feel insecure in their society, and spend more time with online friends, and all of which are problematic in real life [13]. Therefore, researchers have argued that users addicted to Internet games are aggressive and have disorders, such as insomnia, anxiety, and vision syndrome. Internet game users are loyal. VR technology maybe useful, but its excessive use may influence addictive behavior. Moreover, VR technology has been used for treatment and in learning environments in the beginning, but researchers believe that consumers' access to VR has a negative impact on their behavior [14]. Considering previous research, the present study finds no statistical evidence that has used VR and e-games together. The VR gaming industry is growing slowly because of the cost of the required equipment and the few games on the market. Furthermore, researchers believe that the decreasing prices of VR headsets and software may lead consumers toward pornography and VR game addiction (VAD) [15]. Moreover, previous papers have mainly focused on other ICT addictions, such as SNS, games, and online gambling, as mentioned in Appendix A (Supplementary Materials). The present study helps to enrich the current literature on the dark aspect of VR, specifically VAD.

\section{Theoretical Framework}

VR research studies are ongoing in different fields, including architectural [16], medical [17, 18], and education [19] fields, because of the development in VR technologies and the rise of the VR industry. The technology acceptance model (TAM) was the paradigm most narrowly tailored to illustrate customers' expectations and interventions about devices [20]. VR technology was used in different experiments by incorporating external influences [21]. Technology acceptance theories primarily focus on benefits and overlook the critical assessments of consumer's potential risks [22, 23]. These include TAM2 [24], UTAUT [25], and UTAUT2 [26], which demonstrate the development of technical adaptation models over time. Nevertheless, none of the technologyrelated behavioral models was suitable to underline the dark side of technological progress. The present study proposed that high media richness appreciates the user's VR addictive nature to games. In conceptual terms, technological attributes (i.e., VR interactivity (VRI), self-efficacy, and realism) and cognitive attributes (e.g., perceived experience and satisfaction) map the distal and proximal factor spectrum. Previous studies have identified the cognitive-behavioral framework of the problematic use of IT and the combined results of distal and proximal causes. The cognitive-behavioral framework emphasizes thoughts as a significant cause of unusual behavior [27] but is unable to affect problematic use directly as opposed to proximal factors, which are the main attribute of distal causes to factors that contribute significantly to the problematic use of IT [28]. The present study proposed that high media richness increases individuals' game addiction. In other words, it urges irresistible desire [29] and related emotion, which can be mapped in terms of cognitive-behavior modeling [30]. Thus, this study adopted a cognitive-behavioral framework, which identified problematic Internet usage with the combined results of distal and proximal causes. Distal causes 
emphasize the factors that indirectly activate addiction [28], whereas proximal causes directly contribute to developing VAD. This paradigm is widely used for different types of behavioral addictions [30], such as game addiction [31]. The cognitive-behavioral model provides a logical basis to explain emotional dependence [32]. Thus, this study assumed and attempted to verify that the cognitive-behavioral framework is exceptionally suitable to map VAD.

For distal cause, the constructs of perceived quality (PQ), VR self-efficacy (VSE), and VRI are considered absolute terms to define the scale of VAD. Hwang and Kim [33] referred to a positive association between brand usage and user experience, which is linked with the users' $P Q$. Moreover, a service's PQ and technology advancement with brand extension have optimistic domination over the user's satisfaction, willingness to use, purchase of the game, and purchase of additional offers by the provider. Bandura [34] derived self-efficacy from social cognitive theory; furthermore, several studies have argued that self-efficacy could be defined as the individuals' confidence level and ability to tackle unambiguous behavior [35]. Moreover, self-efficacy has beneficial and bleak effects on gamers' behavior, depending on their personality [36]. Specifically, VSE is used as a unique contribution to the current context. The authors assumed VSE as a game player's level of understanding and access to equipment and interfaces with VR games. Thus, VSE is assumed to be one of the most important factors to define VAD. VRI is a state where users participate and modify in real-time. Previous studies have argued that interactivity contributes to VAD and impacts an individual's cognitive growth and social routine $[37,38]$.

Proximal causes emphasize constructs that hold a direct effect on consumers' game addiction. First, this study considers VR realism (VRR), which is followed by consumers' cognitive satisfaction. Proximal causes directly contribute to game addiction as a behavioral outcome. VRR has a significant contribution to VAD. Previous studies have argued that the actual purpose of VR is to enhance realism such that players can experience and enjoy the game better. Formulators should concentrate on many particular aspects, particularly realism, to attract users [39]. Moreover, studies have argued that realism and the feeling of presence could affect users' emotions, which can negatively and positively affect their attitude [40]. The present study did not find any studies that argued or discussed possible factors related to VRR and game addiction having inter-related connections. Thus, the authors assumed that VRR is one of the most important factors to measure the addictive behavior of the game players, particularly VR game players in the modern era. Moreover, studies have argued that access to related resources encourages individuals' sense of satisfaction. Positive and negative satisfaction can be created with unbiased dimensions of psychosomatic requirements [41]. Moreover, evidence shows that satisfaction and dissatisfaction explain significant factors in IGD [41]. Wu et al. [42] conducted a study in China, concluded that satisfaction is significantly negatively associated with problematic video game playing and argued that competence satisfaction and autonomy show indirect effects on game users' life [43].
Therefore, VR cognitive satisfaction (VCS) is the proximal cause of VR-based EPC addiction. Becker and Murphy [44] stated that addiction rationality applies to a coherent strategy of balanced expectations for the anticipation of future decisions and the maximization of use over time. In the context of VAD, the authors hypothesized PQ, VSE, and VRI as distal causes that further lead to VRR and VCS as proximal causes of VAD in society.

A new study project adopted virtual realism as VR technology and VCS as the neurological component of proximal triggers for individuals with gaming addiction. VRR is a state where users realistically feel the environment. The VR project perfectly simulates virtual realism besides technological advancement because it guarantees valid knowledge about the scenario [45]. Users tend to play VR games because of their rich environment and realism. VRR has an immersive environment, where an individual feels a customized and personal experience. In this context, VRR can be proposed as a proximal cause while mapping VAD. In comparison, the literature suggests a feeling of satisfaction with exposure to the games concerned, and this feeling may contribute to addictive behavior. Moreover, players always give positive feedback to express their satisfaction in playing video games [46]. Thus, the authors conclude that VRR and VCS can be captioned as the proximal causes of VR-based EPC addiction.

3.1. Distal Causes (Excitement, Interactivity, and Efficacy). Zeithaml [47] stated that perceived experience excitement (PEX) is "the customer measure of product/service perfection or dominance." Bitner and Hubbert [48] described it as "the general impression of the customer of an institution and its services' relative dominance or inferiority." Hwang and Kim [33] propose that a positive association between brand usage and user experience is linked with users' PEX. Moreover, services' PEX and technology advancement with brand extension have been observed to positively influence users' satisfaction, willingness to use, purchase of the game, and purchase of the additional offers by the provider [49]. In the last few decades, the widespread use of Internet and web technologies and the implications for every aspect of society have led to the technological revolution. The literature contains full accounts on the web technology integration of organizations of various types and sizes. Experience is not a new concept in IT. Practitioners of information systems have always known the necessity to improve the functioning of information systems to react to external and internal pressures and meet critical problems for its growth and survival. Consumer fidelity for Internet games is difficult and expensive [4] and requires a consumer-friendly service to experience excitement. Numerous surveys have found that the increased perception of customer service and excitement results in increased profitability (satisfaction) [50]. Studies have suggested that PEX is an essential part of a store's image and can influence the behavior of gamers in the new electronic environment. Increasing the level of realism is important to generate more excitement [51]. Slater et al. [52] stated that VRR causes a high level of presence and produces 
excitement in users. No study has used excitement with VRR. Thus, the present study proposed the following hypotheses:

H1: Perceived VR experience excitement holds a significant effect on the proximal causes (VRR and VSC) of VAD.

Bandura's [53] personal cognitive philosophy revolves around the concept of self-efficacy. Self-effectiveness refers to an evaluation of people's ability to develop and execute action courses needed to achieve success [34]. It is unique to the area and significantly linked to behavior. Self-effectiveness is about the skills and having the trust to use those skills [54]. Psychological literature shows that self-confidence or self-control and self-efficiency are individual resources [55]. Compared with other personal psychosomatic factors (i.e., self-esteem), self-efficacy encourages the self-appreciation of persons for their capability to perform a given task and accomplish a particular purpose. The authors identified different areas of self-efficiency on this theoretical basis. Self-efficiency in several areas, such as learning [56], worker behavior [57], user responses [58], and video gaming [59], has been examined and validated. In the self-efficiency literature, different technologies were explored, such as the self-efficacy of the computer or the Internet [60]. However, the study has seldom examined the self-efficacy of the video game or online shopping sector. The only study conducted by Ketelhut [59] analyzed the scope of self-efficacy with video games by incorporating self-effectiveness while playing video games. Some studies have used general self-efficacy and personality with games [61]. Moreover, selfefficacy rises to favorable feelings (satisfaction) when computers are experienced and used and is only possible with the trust of users [62]; VR HDM provides a sense of realism [63], where users' self-efficacy pushes them to use VR. Similarly, no research has discussed the use of VSE with VAD. Therefore, the authors assumed that VSE is the most crucial factor in VAD. On the basis of the above arguments, the present study proposed the following hypothesis.

$\mathrm{H} 2$ : VSE holds significant effects on the proximal causes (VRR and VSC) of VAD.

Consumers participate in a virtual environment for fun, socialization, and interactivity [64]. Therefore, brands create products that allow consumers to be highly involved and have the meaning of using VR gadgets. Studies have found that users lose the sense of experience and interactivity in online shopping. Similarly, the degree of interactivity may affect the sense of telepresence. Bogost [65] argued that the interactivity of the game could give users a top scale of experience and enjoyment (satisfaction). Juul [66] illustrated Doom II and stated the difficulty to find the expanse between story-time, narrative-time, and viewing-time. Moreover, he argued that the narration of the game and interactivity cannot be felt at the same time.
Furthermore, interactivity allows users to decorate themselves according to their preference. Belk [67] argued that users believe that the avatar should be like the users. Interactivity also allows users to make their indent in the virtual world according to their preference. Realism in the virtual world makes users more interactive in a realistic manner through their own created and specially designed avatar. In addition, interactivity increases user satisfaction, but their satisfaction decreases because they do not gain new adventures in games. The authors assume that VRI is one of the essential factors for adopting addictive behavior, specifically in VAD. Therefore, the present study proposed the following hypothesis.

H3: VRI holds significant effects on the proximal causes (VRR and VSC) of VAD.

3.2. Proximal Causes (Realism and Cognitive Satisfaction). The social scientist Murphy [68] performed a comprehensive literary analysis of VR to confirm and expand the "commonsense assertion that VR" feels true "rather than conventional screen-based games." Realism is with an essential concept within the artistic culture and is plausibly seen as more practical than others for some aesthetic technologies and forms, including VR. Realism is also of significant interest to art theorists, even if it has always contributed to conflict and discussion. The real main question is whether specific media models are more realistic than others and, if so, what this realism is. Chalmers [69] disputed that VR entity can be considered to include fantasy when an imaginary environment, artifacts, or characters are portrayed at any point by certain VR events. The most crucial purpose for the representation of the literature is to use VR in video games. Moreover, other situations use VR to mediate a nonfictional experience with real things in the real world. Disney's work on ball capturing in virtual worlds is one event. Robson and Tavinor [70] insisted that the ball-grabbing case may be described as "aggressive reality" if an encounter with a simulated cannibal is deemed to be "true fictionality." Moreover, studies have suggested that VR can create a highly realistic environment that can negatively impact users' addictive behavior [71]. Therefore, the authors assume that VRR is one of the most important and significant factors and leads users toward addictive behavior. Thus, the present study proposed the following hypotheses:

H4: VRR positively influences VAD.

Oliver [72] pointed out that satisfaction is the aftersales appraisal of the customer and an affective reaction to the overall experience of products or services. Research has suggested that the performance of users is measured by two major dependent variables, namely, machine fear (computer anxiety) and happiness (satisfaction) [62]. Positive feedback and enjoyment can be gained by using virtual simulation games. Consumers are more pleased with the use of model games when they believe that they are characters with positive results [73]. Studies have shown that satisfaction is closely 
related to the user profile created by consumers on VR [74]. Lu and Wang [75] stated that addiction to gambling contributed directly to loyalty and reduced loyalty to satisfaction. Researchers have claimed that their results partially clarified why online gamers remain loyal even if they are disappointed [4]. In daily life and video games, fulfillment and dissatisfaction with core psychological needs are accurate predictors of IGD. Powerful video games have to meet players' needs and make them incredibly pleased. They can also make the games risky, mostly for people whose psychosomatic needs are not satisfied in the real world. Consequently, the authors assumed that VR content is one of the most significant and essential factors, assuming that game satisfaction leads users to an IGD. Misra et al. [46] found that emotional dependence (satisfaction) is a significant predictor of game addiction behavior. Therefore, the present study proposed the following hypothesis.

H5: VCS positively influences VAD.

3.3. Moderating Role of VR Affordance (VA). Shin [76] claimed that, for the operation to be accepted, affordance should be correctly viewed by consumers; inquiring how VA is obtained for the industry and the academia is necessary. Nelson et al. [77] acknowledged the idea of affordance as an important tool to explore how VR is united by various interaction trends. Moreover, researchers have discussed [76] presence affordance, questioned whether the existence of VR influences user sensation, and discussed the difference between technical and emotional affordability, which contributes to behavioral shifts in the perception of the consumer. Furthermore, a study related affordance and satisfaction in consumer behavior, but no study has used affordance and VCS together. Ke et al. [19] used affordance in a virtual learning environment, but no study has used affordance and VRR in games, specifically VR games. Based on this argument, the authors assumed that VA is a moderator in modeling for VRR and VCS, which means that the function of VRR and VCS in creating enjoyment in the VR game would cause addictive behavior.

H6: VA (in economic terms) moderates the relationship between proximal causes (VRR and VCS) and VAD behavior.

\section{Methodology}

4.1. Participants. VR game players were approached in the referral network and accessible gaming zones and cafes in different cities of Anhui (which can be considered as a kind of convenience sampling). However, to maximize the data response rate and coverage of the population, different regions within the mainland were considered. Overall, during the data collection phase, more than 900 VR game players were approached or invited within mainland China. However, 684 respondents were recorded. Among the collected responses, 109 were rejected due to incomplete and ambiguous responses. The survey rate is $63.88 \%$. The demographics of the collected response set of 575 were explored. The sample size was acceptable according to Cochran. The $t$-test was computed to examine the validity and reliability (nonresponse biases) of the collected sample. The difference between the initial and later collected subsets of the collected sample was checked. The sample can be classified as nonresponse and bias-free based on computed results because no difference was noted among the subset of the collected sample. Table 1 holds the demographic profile of respondents.

4.2. Development of Instruments. The items were taken from authentic sources and were used in different contextual scenarios to ensure reliability and validity. PEX was mapped using three items on VR-based experience excitement and enjoyment from Tokel [78]. VSE was reflected in the three-item instrument, which emphasizes consumers' ability, skills, and confidence in ability and skills in using VR gadgets [79]. VRI was highlighted by the three-item scale, which discussed consumers' participation in the VR environment for interactivity, fun, and visual perspectives, adopted from Kim and Jae [80]. VRR was measured by instruments (items) adopted from Ribbens et al. [81] to emphasize consumers' perception of the VR environment as real in the context of VR addiction. VCS was reflected by a three-item scale adapted from Kim et al. [82] to capture consumers' cognitive satisfaction. VAD was reflected by a three-item scale adopted from Gong et al. [83] to emphasize consumers' VR addiction and related effects. VA was represented by VR hardware purchase intentions, which were measured by a three-item scale proposed by Manis and Choi [84] to capture the effect of consumers' intentions to purchase VR hardware as inventory/resource; this effect can be examined while defining the association of VRR and VCS (as proximal causes) and VR addiction. A Likert scale, which ranges from 1 as highly disagree to 5 as highly agree, was employed to measure each construct. Table 2 shows a list of items adapted.

An instrument with three main sections was developed to collect reliable responses. The first section introduced the purpose of the study. The second section presented the questions related to demographics. The third section enclosed the construct items to collect responses using the Likert scale. To ensure the quality of data collection, reverse coded items were included in the questionnaire, and responses with ambiguities were excluded. To accommodate the concerns related to comprehension and meaningful communication, a prior study was piloted with 25 respondents in the study area. The revised questionnaire was adopted on the basis of suggestions and observations made by participants of the pilot study. The digital medium was considered such that the target population (generation $\mathrm{Z}$ ) can be approached and invited to participate in the survey. To maximize the response rate, the hyperlink for the survey was shared through the social networking application "WeChat." Data were collected throughout the second and third quarters of 2019. 
TABLE 1: Surveyed sample profile.

\begin{tabular}{lccc}
\hline Characteristic & Detail & Frequency & Percentage \\
\hline \multirow{2}{*}{ Gender } & Male & 440 & 76.50 \\
& Female & 135 & 23.50 \\
\hline \multirow{3}{*}{ Age } & Under 20 & 413 & 26.78 \\
& $20-25$ & 8 & 01.83 \\
\hline \multirow{2}{*}{ Using VR to play games for the last } & Above 25 & 149 & 390 \\
& Less than 12 months & 126 & 52.17 \\
\hline
\end{tabular}

TABle 2: Constructs, instruments, and sources.

\begin{tabular}{|c|c|c|c|}
\hline Construct & Code & Items description & Source \\
\hline $\begin{array}{l}\text { Perceived experience excitement } \\
\text { (PEX) }\end{array}$ & $\begin{array}{l}\text { PEX1 } \\
\text { PEX2 } \\
\text { PEX3 }\end{array}$ & $\begin{array}{l}\text { I find playing VR games enjoyable } \\
\text { I find playing VR games pleasant } \\
\text { I have fun playing VR games }\end{array}$ & {$[78]$} \\
\hline VR self-efficacy (VSE) & $\begin{array}{l}\text { VSE1 } \\
\text { VSE2 } \\
\text { VSE3 }\end{array}$ & $\begin{array}{l}\text { I am confident and can understand the basic concepts of a VR environment } \\
\text { I am confident that I can excellently perform while using a VR environment } \\
\text { I expect to do well in a VR environment }\end{array}$ & {$[79]$} \\
\hline VR interactivity (VRI) & $\begin{array}{l}\text { VRI1 } \\
\text { VRI2 } \\
\text { VRI3 }\end{array}$ & $\begin{array}{l}\text { I feel that I have a lot of control over the content of the game } \\
\text { I interactively play a VR game } \\
\text { I feel I can control my visual perspective }\end{array}$ & [80] \\
\hline VR realism (VRR) & $\begin{array}{l}\text { VRR1 } \\
\text { VRR2 } \\
\text { VRR3 }\end{array}$ & $\begin{array}{l}\text { While playing this game, I felt like I was present in the video game world } \\
\text { While playing this game, I felt that I was part of the video game world } \\
\text { While playing this game, I felt as if I was a part of the action }\end{array}$ & [81] \\
\hline VR cognitive satisfaction (VCS) & $\begin{array}{l}\text { VCS1 } \\
\text { VCS2 } \\
\text { VCS3 }\end{array}$ & $\begin{array}{l}\text { My choice to use VR games was a wise one } \\
\text { The VR games provide me with a real environment, which I idealize } \\
\text { VR games provide me with what is needed from a gaming environment }\end{array}$ & {$[82]$} \\
\hline VR game addiction (VAD) & $\begin{array}{l}\text { VAD1 } \\
\text { VAD2 } \\
\text { VAD3 }\end{array}$ & $\begin{array}{c}\text { Using VR games sometimes interferes with other things } \\
\text { When I play VR games, I often feel agitated } \\
\text { I have made unsuccessful attempts to reduce the time I use VR gadgets to play } \\
\text { games }\end{array}$ & [83] \\
\hline VR affordance (VA) & $\begin{array}{l}\text { AV1 } \\
\text { AV2 } \\
\text { AV3 }\end{array}$ & $\begin{array}{l}\text { The likelihood that I will purchase VR hardware within the foreseeable future is } \\
\text { high } \\
\text { I intend to purchase VR hardware within the foreseeable future } \\
\text { Purchasing VR hardware in the foreseeable future is important to me }\end{array}$ & [84] \\
\hline
\end{tabular}

4.3. Data Analysis. The current research employed the MLE method to construct a structural equation model, by which learners' VR consumption behavior was examined. The bootstrapping method was adopted to explore further the mediation of VRR and the moderation of VA on learners' VAD.

SEM is a reliable approach to illustrate the relations between variables and latent constructs systematically and simultaneously. Statistically, MLE is typically employed as a universal theory estimation technique to estimate the parameters of a probability distribution by maximizing a likelihood function simultaneously. The point that maximizes the likelihood function in the parameter space is regarded as the MLE. As shown in equation (1), a $\left\{\mathbf{x}_{1}, \mathbf{x}_{2}, \ldots\right.$, $\left.\mathbf{x}_{n}\right\}$ random sample is assumed to have descended from a multivariate normal distribution $N\left(\boldsymbol{\mu}_{0}, \boldsymbol{\Sigma}_{0}\right)$. Assuming a population matrix function with $\boldsymbol{\Sigma}_{0}, q \times 1$ size, and $\boldsymbol{\theta}_{0}$ unknown parameter, $\boldsymbol{\Sigma}_{0}=\boldsymbol{\Sigma}\left(\boldsymbol{\theta}_{0}\right)$ is achieved. In this case, $\operatorname{tr}$ denotes the trace of a matrix, $\mathbf{S}$ denotes the sample covariance matrix, $p$ indicates the number of manifests, and the variable $\boldsymbol{\Sigma}\left(\boldsymbol{\theta}_{0}\right)$ represents the covariance matrix of the hypothesized model (Cangur and Ercan):

$$
F_{\mathrm{MLE}}(\boldsymbol{\theta})=\log \sum(\boldsymbol{\theta})+\operatorname{tr}\left(\mathbf{S} \sum(\boldsymbol{\theta})^{-1}\right)-\log \mathbf{S}-p .
$$

In response to the flexibility and intuition of maximum likelihood, the method was dominantly utilized as a means of statistical inference in SEM.

\section{Analysis}

The current subsection started with the reliability testing of the collected survey and was followed by hypotheses testing, which included mediation and moderation examination. CFA was conducted, which comprised inter- and intraconstruct level measures, as presented in Table 3.

Table 4 shows that external reliability computed further the examination of recorded AVE scores for each construct and its square root, which is recommended to be above the interconstruct correlation scores, as advised by the previous 
TABLE 3: Reliability and validity analysis through CFA.

\begin{tabular}{|c|c|c|c|c|c|}
\hline Construct & Items & $\Lambda$ & $\alpha$ & CR & AVE \\
\hline \multirow{3}{*}{ Perceived experience excitement (PEX) } & PEX1 & 0.832 & \multirow{3}{*}{0.776} & \multirow{3}{*}{0.855} & \multirow{3}{*}{0.662} \\
\hline & PEX2 & 0.819 & & & \\
\hline & PEX3 & 0.790 & & & \\
\hline \multirow{3}{*}{ VR self-efficacy (VSE) } & VSE1 & 0.804 & \multirow{3}{*}{0.824} & \multirow{3}{*}{0.810} & \multirow{3}{*}{0.587} \\
\hline & VSE2 & 0.753 & & & \\
\hline & VSE3 & 0.741 & & & \\
\hline \multirow{3}{*}{ VR interactivity (VRI) } & VRI1 & 0.847 & \multirow{3}{*}{0.848} & \multirow{3}{*}{0.870} & \multirow{3}{*}{0.691} \\
\hline & VRI2 & 0.830 & & & \\
\hline & VRI3 & 0.816 & & & \\
\hline \multirow{3}{*}{ VR realism (VRR) } & VRR1 & 0.851 & \multirow{3}{*}{0.874} & \multirow{3}{*}{0.863} & \multirow{3}{*}{0.678} \\
\hline & VRR2 & 0.833 & & & \\
\hline & VRR3 & 0.784 & & & \\
\hline \multirow{3}{*}{ VR cognitive satisfaction (VCS) } & VCS1 & 0.844 & \multirow{3}{*}{0.903} & \multirow{3}{*}{0.878} & \multirow{3}{*}{0.706} \\
\hline & VCS2 & 0.839 & & & \\
\hline & VCS3 & 0.838 & & & \\
\hline \multirow{3}{*}{ VR game addiction (VAD) } & VAD1 & 0.866 & \multirow{3}{*}{0.864} & \multirow{3}{*}{0.849} & \multirow{3}{*}{0.655} \\
\hline & VAD2 & 0.861 & & & \\
\hline & VAD3 & 0.688 & & & \\
\hline \multirow{3}{*}{ VR affordance (VA) } & VA1 & 0.960 & \multirow{3}{*}{0.936} & \multirow{3}{*}{0.958} & \multirow{3}{*}{0.884} \\
\hline & VA2 & 0.935 & & & \\
\hline & VA3 & 0.926 & & & \\
\hline
\end{tabular}

TABLE 4: Correlation scores and external validity test.

\begin{tabular}{|c|c|c|c|c|c|c|c|c|c|}
\hline Construct & $\mathrm{M}(\mathrm{SD})$ & VIF & PEX & VSE & VRI & VRR & VCS & VAD & VA \\
\hline PEX & $2.826(.827)$ & 1.177 & 0.813 & & & & & & \\
\hline VSE & $3.957(.827)$ & 1.572 & $0.264^{* *}$ & 0.766 & & & & & \\
\hline VRI & $2.769(.770)$ & 1.387 & $0.339^{* *}$ & $0.353^{* *}$ & 0.813 & & & & \\
\hline VRR & $3.502(.821)$ & 1.576 & $0.251^{* *}$ & $0.466^{* *}$ & $0.459^{* *}$ & 0.823 & & & \\
\hline VCS & $4.012(.631)$ & 1.549 & $0.259^{* *}$ & $0.533^{* *}$ & $0.304^{* *}$ & $0.468^{* *}$ & 0.840 & & \\
\hline VAD & $3.840(.645)$ & -- & $0.189^{* *}$ & $0.601^{* *}$ & $0.290^{* *}$ & $0.404^{* *}$ & $0.506^{* *}$ & 0.809 & \\
\hline VA & $3.583(.824)$ & 1.012 & 0.040 & 0.015 & 0.059 & $0.085^{*}$ & 0.071 & 0.015 & 0.940 \\
\hline
\end{tabular}

literature [85]. Multicollinearity is a challenge for regression analysis and is calculated by recording the VIF scores of each construct, which were observed within the continuum of 1.012 to 1.576 , as advised by Hair et al. [86]. To examine data reliability, Harman's approach was used to examine factor analysis. Podsakoff et al. [87] recommended the upper cut off limit of $50 \%$ by examining a single factor. In the current study, the construct with $29.24 \%$ variance was recorded, which indicated that no single factor compromised the proposed model. These results allowed the researchers to proceed with the computation for hypotheses testing.

In the structural model, the chi-square value was 425.147, and the degree of freedom was124. All the fitness indices in Table 5 were within the satisfactory threshold limits, as advised by $\mathrm{Hu}$ and Bentler [88].

The explanation is extracted by using statistical tools (SPSS-Statistics and AMOS), which computed the standardized estimates. The proposed demographic constructs (as control factors) were significant and had noticeable scores while measuring VR addiction. The determinate constructs in the proposed model, namely, VRR, VCS, and $\mathrm{VAD}$, were noted with a variance of $40.3 \%, 36.7 \%$, and $38.9 \%$, respectively. The study observed PEX as the least
TABle 5: Model fitness indices computed through AMOS.

\begin{tabular}{lccc}
\hline Fitness indices & Recommended value & Measurement & Proposed \\
\hline Chi-square & & 320.224 & 425.147 \\
Df & & 120 & 124 \\
Chi-square/d $f$ & $\leq 5.0$ & 2.669 & 3.068 \\
GFI & 0.90 & 0.943 & 0.938 \\
AGFI & 0.85 & 0.919 & 0.909 \\
TLI & 0.95 & 0.957 & 0.946 \\
IFI & 0.95 & 0.966 & 0.959 \\
NFI & 0.95 & 0.947 & 0.941 \\
CFI & 0.95 & 0.966 & 0.959 \\
RMSEA & $\leq 0.08$ & 0.054 & 0.060 \\
\hline
\end{tabular}

Note. $\mathrm{d} f=$ degree of freedom; GFI, AGFI, TLI, NFI, CFI, and RMSEA = recommended values followed cutoffs, as advised by $\mathrm{Hu}$ and Bentler [88].

influencing factor while defining VRR and VCS. PEX's effect on VRR was insignificant, and that on VCS was minimal, as listed in Table 6.

This argument led to findings from the literature, which reflected that consumers' excitement to experience VR gadgets did not necessarily explain their after-use satisfaction and perception that the VR environment is real. The 
TABle 6: Hypotheses testing (path analysis).

\begin{tabular}{|c|c|c|c|c|}
\hline Sr. & Description & $\begin{array}{c}\text { Beta } \\
(\beta)\end{array}$ & Significance & Result \\
\hline $\mathrm{H} 1$ (a) & $\mathrm{PEX} \longrightarrow \mathrm{VRR}$ & 0.032 & $p \geq 0.05$ & $\begin{array}{c}\text { Not } \\
\text { supported }\end{array}$ \\
\hline $\mathrm{H} 1(\mathrm{~b})$ & $\mathrm{PEX} \longrightarrow \mathrm{VCS}$ & 0.100 & $p \leq 0.05$ & Supported \\
\hline $\mathrm{H} 2(\mathrm{a})$ & $\mathrm{VSE} \longrightarrow \mathrm{VRR}$ & 0.366 & $p \leq 0.001$ & Supported \\
\hline $\mathrm{H} 2$ (b) & $\mathrm{VSE} \longrightarrow \mathrm{VCS}$ & 0.523 & $p \leq 0.05$ & Supported \\
\hline $\mathrm{H} 3(\mathrm{a})$ & $\mathrm{VRI} \longrightarrow \mathrm{VRR}$ & 0.384 & $p \leq 0.001$ & Supported \\
\hline $\mathrm{H} 3$ (b) & $\mathrm{VRI} \longrightarrow \mathrm{VCS}$ & 0.100 & $p \leq 0.001$ & Supported \\
\hline $\mathrm{H} 4$ & $\mathrm{VRR} \longrightarrow \mathrm{VAD}$ & 0.179 & $p \leq 0.001$ & Supported \\
\hline H5 & $\mathrm{VCS} \longrightarrow \mathrm{VAD}$ & 0.240 & $p \leq 0.001$ & Supported \\
\hline H6(a) & $\mathrm{VRR}^{*} \mathrm{VA} \longrightarrow \mathrm{VAD}$ & 0.087 & $p \leq 0.05$ & Supported \\
\hline H6(b) & $\mathrm{VCS}^{*} \mathrm{VA} \longrightarrow \mathrm{VAD}$ & 0.026 & $p \geq 0.05$ & $\begin{array}{c}\text { Not } \\
\text { supported }\end{array}$ \\
\hline
\end{tabular}

highest impact on VRR was observed by VRI. Consumers' VRI enhanced their perception about the VR environment as real. The second highest effect for VRR is observed by VSE. Consumers have confidence in their ability to use VR gadgets and are likely to perceive the VR environment as real. VSE explained that VCS is stronger than VRI. VSE has a strong impact on VCS. In other words, high self-efficacy to operate and use VR gadgets enhances consumers' satisfaction because more control provides less cognitive dissonance, which makes them more confident and satisfied. While incorporating the effects of endogenous variables, Figure 1 shows that VCS had more explanatory power than VRR in explaining VAD.

The results indicated some interesting findings of the study "VR environment as if real," which showed less effect on VAD than consumers' cognitive satisfaction on VAD. The results concluded that high cognitive satisfaction makes consumers more addicted than experiencing the VR environment as real. The moderation effect of VA was minimal in the case of VRR, where its impact in the case of VCS was insignificant. The results emphasized that VA moderated the effect of VRR in explaining VR addiction but did not perform this moderation in the case of VCS and VAD.

The present study employed Preacher and Hayes's [89] approach to quantify and measure the mediating behavior of the proposed factors (VRR and VSC). Through the recommended approach, the scores of the confidence intervals (CIs) of the bootstrapping method were employed, and CIs computed for each of the hypotheses were satisfactory and are documented in Table 7.

Baron and Kenny followed test mediation. The outputs from the adopted method are listed in Table 8. The present study can conclude that the sense of realism and cognitive satisfaction in the context of VAD usage behavior are partial mediators while examining the role of interactivity, excitement, and self-efficacy of VR content consumption among VR game users.

\section{Discussion}

This study has two main findings. First, VSE has a significant role as an exogenous factor while measuring VAD among consumers. Second, VCS has a strong significant association with VAD. Similarly, the authors found that the respondents believe that VSE is a dominating contributor in defining VRR and cognitive satisfaction and creates an addiction to VR games; VSE has a significant hold while mapping the perception and actions of VR game players [61]; the authors also found that VSE has a nonsignificant role in leading VRR to game addiction. Moreover, VRI was observed to be the strongest proposed candidate to define VRR. Studies have suggested immediate interaction on player participation [90], which had a strong effect on addictive behavior. Previous literature has supported the relationship between PEX and VRC. The results created negative and positive emotions.

Furthermore, researchers have argued that felicitous music followed cheerful endings, where in a character experiences joy and satisfaction over a defeated enemy [91]; however, in the current study, observing the fully mediating role of VSC and understanding the relationship between PEX and addiction contributed to the literature. This study concluded that PEX holds a unique behavior while mapping VAD. While defining VAD, VRR was observed to be less dominant to VSC. Moreover, VRR was not as highly significant as VSC when adopting addictive behavior toward VR games. VA was found to be psychological but not from an economic perspective. Furthermore, VA was considered an individual's stance toward the adoption of VR gadgets. VA did not create satisfaction among users who can afford VR for VRR.

6.1. Theoretical Implications. This study provided profound and useful additions to the academic literature. First, this study is the first of its nature to understand the behavior of VAD. Previous studies have been conducted with other research factors, whereas the present study used the behavioral aspect/change of gamers from a multiperspective approach, which enhanced the comprehension of gamers' behavioral changes. Moreover, VSE was used to inquire and understand gamers' addictive behavior toward VR games. Second, this study is highly unique compared with previous studies. Few studies have been found where researchers have adopted gaming addiction with behavioral modeling, specifically in the context of VR games. The authors adopted cognitive behavioral modeling. Previous studies have concluded that excess usage of video games could have a serious health concern [92]. Gackenbach et al. [93] stated that, besides addiction, serious physical health concerns are dangerous for users who excessively use Internet games. The present study used the instrument of VSE, whereas previous studies have not used it, specifically in the context of game addiction. Therefore, the authors claimed that this usage is the novelty of this study. Moreover, VRI and VSE are the novelty in the context of games. The authors examined published studies and did not find any data that used VRI or VSE in the context of games.

Furthermore, the authors found that PEX fully mediates VCS and VAD, which means that VCS can create a strong addiction behavior when it comes to PEX and VCS. For 


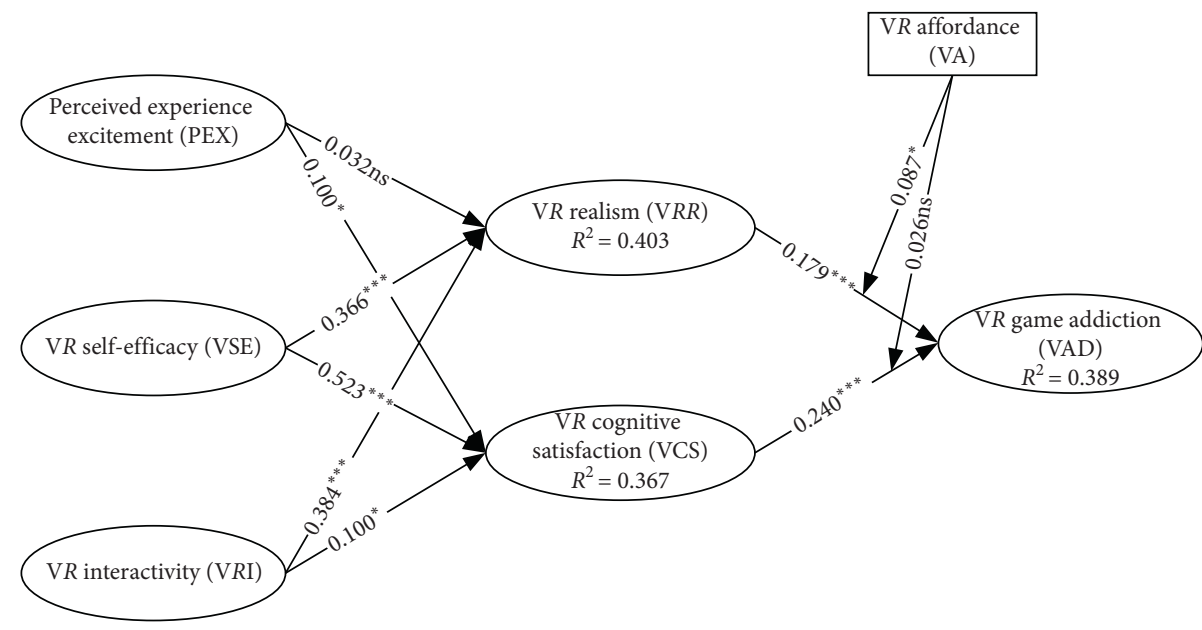

FIGURE 1: Graphical view of the path analysis of the proposed model.

TABle 7: Mediation analysis (by bootstrapping).

\begin{tabular}{|c|c|c|c|c|c|c|c|c|c|c|}
\hline Нypo & IV & M & DV & $\begin{array}{l}\text { Effect of IV on M } \\
\text { (a) }\end{array}$ & $\begin{array}{c}\text { Effect of } M \text { on DV } \\
\text { (b) }\end{array}$ & $\begin{array}{l}\text { Direct } \\
\left(c^{\prime}\right)\end{array}$ & $\begin{array}{c}\text { Indirect } \\
\left(\mathrm{a}^{*} \mathrm{~b}\right)\end{array}$ & $\begin{array}{l}\text { Total effect } \\
\text { (c) }\end{array}$ & $95 \%(\mathrm{CI})$ & Mediation \\
\hline $\mathrm{H} 7(\mathrm{a})$ & PEX & VRR & VAD & $0.249^{* * *}$ & $0.164^{* * *}$ & $0.025^{\mathrm{ns}}$ & $0.040^{* *}$ & $0.147^{* * *}$ & $\begin{array}{l}(0.020, \\
0.064)\end{array}$ & Supported \\
\hline $\mathrm{H} 7(\mathrm{~b})$ & VSE & VRR & VAD & $0.693^{* * *} 0.073^{*}$ & $0.508^{* * *} 0.050^{*}$ & $0.702^{* * *}$ & $\begin{array}{l}(0.007 \\
0.095)\end{array}$ & Supported & & \\
\hline $\mathrm{H} 7(\mathrm{c})$ & VRI & VRR & VAD & $0.489^{* * *}$ & $0.140^{* * *} 0.074^{*}$ & $0.067^{*}$ & $0.243^{* * *}$ & $(0.034,0.109)$ & Supported & \\
\hline $\mathrm{H} 8$ (a) & PEX & VCS & VAD & $0.198^{* * *}$ & $0.409^{* * *}$ & $0.025^{\mathrm{ns}}$ & $0.081^{* * *}$ & $0.147^{* * *}$ & $\begin{array}{c}(0.053 \\
0.115)\end{array}$ & Supported \\
\hline $\mathrm{H} 8$ (b) & VSE & VCS & VAD & $0.609^{* * *}$ & $0.236^{* * *}$ & $0.508^{* * *}$ & $0.143^{* * *}$ & $0.702^{* * *}$ & $\begin{array}{l}(0.084 \\
0.205)\end{array}$ & Supported \\
\hline $\mathrm{H} 8(\mathrm{c})$ & VRI & VCS & VAD & $0.249^{* * *}$ & $0.404^{* * *} 0.074^{*}$ & $0.101^{* * *}$ & $0.243^{* * *}$ & $(0.072,0.138)$ & Supported & \\
\hline
\end{tabular}

Table 8: Mediation (as advised by Baron and Kenny's approach).

\begin{tabular}{|c|c|c|c|c|c|c|c|}
\hline \multirow{2}{*}{ Нypo } & \multirow{2}{*}{ IV } & \multirow{2}{*}{ DV } & \multirow{2}{*}{$\mathrm{IV} \longrightarrow \mathrm{DV}$} & \multirow{2}{*}{$\mathrm{IV} \longrightarrow \mathrm{M}$} & \multicolumn{2}{|c|}{$\mathrm{IV}+\mathrm{M} \longrightarrow \mathrm{DV}$} & \multirow{2}{*}{ Mediation } \\
\hline & & & & & $\mathrm{IV} \longrightarrow \mathrm{DV}$ & $\mathrm{M} \longrightarrow \mathrm{DV}$ & \\
\hline $\mathrm{H} 7(\mathrm{a})$ & PEX & $\mathrm{VAD}$ & $0.147^{* * *}$ & $0.250^{* * *}$ & $0.073^{*}$ & $0.299^{* * *}$ & Partial \\
\hline $\mathrm{H} 7(\mathrm{~b})$ & VSE & $\mathrm{VAD}$ & $0.703^{* * *}$ & $0.694^{* * *}$ & $0.616^{* * *}$ & $0.124^{* * *}$ & Partial \\
\hline $\mathrm{H} 7(\mathrm{c})$ & VRI & $\mathrm{VAD}$ & $0.243^{* * *}$ & $0.490^{* * *}$ & $0.111^{* *}$ & $0.269^{* * *}$ & Partial \\
\hline $\mathrm{H} 8(\mathrm{a})$ & PEX & VAD & $0.147^{* * *}$ & $0.198^{* * *}$ & $0.048^{\mathrm{ns}}$ & $0.501^{* * *}$ & Full \\
\hline $\mathrm{H} 8$ (b) & VSE & $\mathrm{VAD}$ & $0.703^{* * *}$ & $0.609^{* * *}$ & $0.541^{* * *}$ & $0.265^{* * *}$ & Partial \\
\hline $\mathrm{H} 8(\mathrm{c})$ & VRI & $\mathrm{VAD}$ & $0.243^{* * *}$ & $0.249^{* * *}$ & $0.126^{* * *}$ & $0.470^{* * *}$ & Partial \\
\hline
\end{tabular}

instance, VSE with realism and satisfaction plays a significant role not only in game addiction but also in general addiction. $\mathrm{VA}$ in an economic perspective strengthens addiction behavior. Similarly, VR satisfaction does not rely on affordance but is an individual act. Using a four-cognitionlevel analysis, the authors found that psychological construct dominates in creating addictive behavior. They also found that a high level of interactivity leads to a high level of game addiction. The authors also suggested that further studies carry out interactivity and self-efficacy and further investigate arcades and VR arcades. Self-efficacy in the games addiction perspective can be further studied. Specifically,
VSE can be studied in the context of different types of games. For instance, VA has been observed while examining individuals' behavior toward game addiction. However, VA's moderating effect while mapping the intentions of individuals was rarely observed. No study has used VA as a moderator for VR games players. The present study is the first to use it.

6.2. Practical Implications. The results of this study showed that VRI creates a high level of satisfaction among users. Similarly, previous studies have suggested that interactivity 
with advanced technology (VR) affects attitude and creates a positive attitude [94]. Moreover, researchers have expressed serious concerns about health and addiction toward Internet games. Gamers' addictions to Internet games have been argued to cause mental health problems [95]. Specifically, among children, the argument is that addiction to games can affect learning and thinking abilities. Similarly, VR games can be restricted with time limitations and demographic usage. VSE is revolving around one's ability to accomplish given tasks. Similarly, from the analysis of the current results, self-efficacy is proven to affect addiction with the help of VRR. Therefore, the quality of games in the sense of realism can be improved to attract the users toward the VR games. Users' involvement becomes more robust when it comes to the sense of realism. Moreover, users feel presence in the game when realism and experience excitement are strong. It can also be used for learning purposes [56]. Studies have indicated that VRR has an important role in learning. For instance, the authors recommend academicians to carry out further research to fill the literature gap on VR games. The environment needs to be more realistic such that users can feel the real sense of presence in the game. The authors did not find any study based on VAD. Thus, VAD can be studied more to fill the literature gap. Satisfaction among users needs excitement and quality experience. To attract users toward VR games, developers need to develop exciting fantasies in the game environment. Balakrishnan and Gri [4] stated that ensuring the loyalty of consumers toward Internet games is difficult; therefore, with the advancement of the technology, more advanced features must be developed to attract users and make them continue playing VR games. Moreover, it can have a negative impact on satisfaction and can disturb the daily routine of users. It can also be considered such that users' daily routines are not disturbed with extra satisfaction. Therefore, satisfied users are likely to experience VAD. The level of satisfaction can be increased for learning or psychological treatment, where students are involved and can learn easily and psychological patients can be treated appropriately. Furthermore, many games require substantial mental ability. Computer games are often considered to be mentally oriented, particularly competitive games.

\section{Conclusion and Limitations}

This study utilized the cognitive-behavioral model to examine users' addiction toward VR games. The authors found that VRI has the uppermost potential for appreciating situations. Similarly, PEX and VSE are shown to have significant deterministic power to explain users' behavior toward game addiction. Moreover, VRR has an important role in creating a negative impact on addiction among users. Games that offer exciting experiences and a sense of realism can be improved such that more users use them. They should be used for academic purposes more than for entertainment. Furthermore, this study focused on the general population, and the focus could be further extended by adding a crosscultural view to find the VR addiction behavior of different countries. Moreover, this study adopted a quantitative survey, and this approach could be improved by adding qualitative techniques for data collection and analysis. This study has the following limitations, which could lead to further studies. First, this study only adopted a cognitivebehavioral frame, which could be further extended and revised with other behavioral methods. Second, this study focused on the general population, which could be further extended to a demographic approach (i.e., gender or socioeconomic factors). Third, this study adopted a quantitative survey, and this approach could be improved by adding qualitative techniques for data collection and analysis.

\section{Data Availability}

The data used to support the findings of this study are available from the corresponding author upon request.

\section{Conflicts of Interest}

No conflicts of interest were found.

\section{Authors' Contributions}

Xuesong Zhai, Fahad Asmi, and Ronting Zhou contributed equally.

\section{Acknowledgments}

This research work was supported by the National Social Science Fund of China (grant ID: 17BXW034) and the 2020 Humanities and Social Science Projects of the Ministry of Education (grant ID: 20YJC880118).

\section{Supplementary Materials}

Appendix A: studies on addictive behavior. (Supplementary Materials)

\section{References}

[1] R. M. Ryan, C. S. Rigby, and A. Przybylski, "The motivational pull of video games: a self-determination theory approach," Motivation and Emotion, vol. 30, pp. 347-363, 2006.

[2] B. Behzadnia, P. J. C. Adachi, E. L. Deci, and H. Mohammadzadeh, "Associations between students' perceptions of physical education teachers' interpersonal styles and students' wellness, knowledge, performance, and intentions to persist at physical activity: a self-determination theory approach," Psychology of Sport and Exercise, vol. 39, pp. 10-19, 2018.

[3] Q.-Q. Liu, D.-J. Zhang, X.-J. Yang, C.-Y. Zhang, C.-Y. Fan, and Z.-K. Zhou, "Perceived stress and mobile phone addiction in Chinese adolescents: a moderated mediation model," Computers in Human Behavior, vol. 87, pp. 247-253, 2018.

[4] J. Balakrishnan and M. D. Griffiths, "Loyalty towards online games, gaming addiction, and purchase intention towards online mobile in-game features," Computers in Human Behavior, vol. 87, pp. 238-246, 2018.

[5] S. Horwood and J. Anglim, "Problematic smartphone usage and subjective and psychological well-being," Computers in Human Behavior, vol. 97, pp. 44-50, 2019. 
[6] A. Błachnio and A. Przepiorka, "Personality and positive orientation in Internet and Facebook addiction. An empirical report from Poland," Computers in Human Behavior, vol. 59, pp. 230-236, 2016.

[7] J. Clement, Number of Monthly Active Facebook Users Worldwide as of 2nd quarter 2019 (in millions), Statista, Hamburg, Germany, 2019.

[8] C. York and J. Turcotte, "Vacationing from facebook: adoption, temporary discontinuance, and readoption of an innovation," Communication Research Reports, vol. 32, no. 1, pp. 54-62, 2015.

[9] T. Nam, "Technology usage, expected job sustainability, and perceived job insecurity," Technological Forecasting and Social Change, vol. 138, pp. 155-165, 2019.

[10] Şö Gökçearslan, F. K. Mumcu, T. Haşlaman, and Y. D. Çevik, "Modelling smartphone addiction: the role of smartphone usage, self-regulation, general self-efficacy and cyberloafing in university students," Computers in Human Behavior, vol. 63, pp. 639-649, 2016.

[11] Q. Jiang, Y. Li, and V. Shypenka, "Loneliness, individualism, and smartphone addiction among international students in China," Cyberpsychology, Behavior, and Social Networking, vol. 21, no. 11, pp. 711-718, 2018.

[12] Ás Zsila, G. Orosz, B. Bőthe et al., "An empirical study on the motivations underlying augmented reality games: the case of Pokémon Go during and after Pokémon fever," Personality and Individual Differences, vol. 133, pp. 56-66, 2018.

[13] F. Bányai, M. D. Griffiths, O. Király, and Z. Demetrovics, "The psychology of esports : a systematic literature review," Journal of Gambling Studies, vol. 35, no. 2, 2018.

[14] H. Cash, C. Rae, A. Steel, and A. Winkler, "Internet addiction: a brief summary of research and practice," Current Psychiatry Reviews, vol. 8, no. 4, pp. 292-298, 2012.

[15] D. L. King and P. H. Delfabbro, "An introduction to gaming and IGD," in Internet Gaming Disorder, pp. 1-21, Academic Press, Cambridge, MA, USA, 2018.

[16] M. E. Portman, A. Natapov, and D. Fisher-Gewirtzman, “To go where no man has gone before: virtual reality in architecture, landscape architecture and environmental planning," Computers, Environment and Urban Systems, vol. 54, pp. 376-384, 2015.

[17] E. K. Yuen, E. M. Goetter, M. J. Stasio et al., "A pilot of acceptance and commitment therapy for public speaking anxiety delivered with group videoconferencing and virtual reality exposure," Journal of Contextual Behavioral Science, vol. 12, pp. 47-54, 2019.

[18] D. Lafortune, L. Dion, and P. Renaud, "Virtual reality and sex therapy: future directions for clinical research," Journal of Sex \& Marital Therapy, vol. 46, no. 1, pp. 1-17, 2019.

[19] F. Ke, M. Pachman, and Z. Dai, "Investigating educational affordances of virtual reality for simulation-based teaching training with graduate teaching assistants," Journal of Computing in Higher Education, 2020.

[20] H. Yang, J. Yu, H. Zo, and M. Choi, "User acceptance of wearable devices: an extended perspective of perceived value," Telematics and Informatics, vol. 33, no. 2, pp. 256-269, 2016.

[21] J. Lee, J. Kim, and J. Y. Choi, “The adoption of virtual reality devices: the technology acceptance model 918 integrating enjoyment, social interaction, and strength of the social ties," Telematics and Informatics, vol. 39, pp. 37-48, 2019.

[22] F. D. Davis, "Perceived usefulness, perceived ease of use, and user acceptance of information technology," MIS Quarterly, vol. 13, no. 3, 1989.
[23] R. Agarwal and E. Karahanna, “Time flies when you're having fun: cognitive absorption and beliefs about information technology usage," MIS Quarterly, vol. 24, no. 4, pp. 665-694, 2000.

[24] V. Venkatesh and F. D. Davis, "Theoretical extension of the technology acceptance model: four longitudinal field studies," Management Science, vol. 46, no. 2, 2000.

[25] V. Vankatesh, M. G. Morris, M. Hall, G. B. Davis, F. D. Davis, and S. M. Walton, "User acceptance OF information technology: toward a unified view," MIS Quarterly, vol. 27, pp. 425-478, 2003.

[26] V. Venkatesh, J. Y. L. Thong, and X. Xu, "Consumer acceptance and use of information technology: extending the unified theory of acceptance and use of technology," MIS Quarterly, vol. 36, no. 1, pp. 157-178, 2012.

[27] R. A. Davis, "Cognitive-behavioral model of pathological Internet use," Computers in Human Behavior, vol. 17, no. 2, 2001.

[28] X. Zheng and M. K. O. Lee, "Excessive use of mobile social networking sites: negative consequences on individuals," Computers in Human Behavior, vol. 65, pp. 65-76, 2016.

[29] E. Karadağ and B. Kılıç, "Öğretmen görüşlerine göre oğrencilerdeki teknoloji bağimliliği," Psikiyatride Guncel Yaklasimlar - Current Approaches in Psychiatry, vol. 11, no. 1, pp. 101-117, 2019.

[30] M. H. Orzack, A. C. Voluse, D. Wolf, and J. Hennen, "An ongoing study of group treatment for men involved in problematic internet-enabled sexual behavior," Cyber Psychology \& Behavior, vol. 9, no. 3, pp. 348-360, 2006.

[31] M. Moital, A. Bain, H. Thomas et al., "The psychology of esports : a systematic literature review," Journal of Gambling Studies, vol. 1321, pp. 1-5, 2018.

[32] C. Wang, M. K. O. Lee, and Z. Hua, "A theory of social media dependence: evidence from microblog users," Decision Support Systems, vol. 69, pp. 40-49, 2015.

[33] S. Hwang and S. Kim, "Does mIM experience affect satisfaction with and loyalty toward $\mathrm{O} 2 \mathrm{O}$ services?" Computers in Human Behavior, vol. 82, pp. 70-80, 2019.

[34] A. Bandura, Social Foundations of Thought and Action: A Social Cognitive Theory/Albert Bandura, Prentice-Hall, Upper Saddle River, NJ, USA, 1986.

[35] N. Jimenez, S. San-Martin, and N. Puente, "The path to mobile shopping compatibility," The Journal of High Technology Management Research, vol. 30, no. 1, pp. 15-26, 2019.

[36] T. Strohäker, "The relationship between self-limitation and gambling behavior among German gambling arcade visitors," Journal of Gambling Studies, vol. 35, no. 4, pp. 1229-1248, 2019.

[37] J.-H. T. Lin, "Fear in virtual reality (VR): fear elements, coping reactions, immediate and next-day fright responses toward a survival horror zombie virtual reality game," Computers in Human Behavior, vol. 72, pp. 350-361, 2017.

[38] B. Y. Park, G. Wilson, J. Berger et al., "Is internet pornography causing sexual dysfunctions? A review with clinical reports," Behavioral Sciences, vol. 6, 2016.

[39] P. Krompiec and K. Park, "Enhanced player interaction using motion controllers for first-person shooting games in virtual reality," IEEE Access, vol. 7, pp. 124548-124557, 2019.

[40] K. Zibrek, S. Martin, and R. McDonnell, "Is photorealism important for perception of expressive virtual humans in virtual reality?" ACM Transactions on Applied Perception, vol. 16, 2019.

[41] B. P. H. Hui, A. M. S. Wu, N. Y. F. Siu, M. L. Chung, and N. Pun, "The effects of need satisfaction and dissatisfaction on 
flourishing among young Chinese gamers: the mediating role of internet gaming disorder," International Journal of Environmental Research and Public Health, vol. 16, pp. 1-14, 2019.

[42] A. M. S. Wu, L. L. M. Lei, and L. Ku, "Psychological needs, purpose in life, and problem video game playing among Chinese young adults," International Journal of Psychology, vol. 48, no. 4, pp. 583-590, 2013.

[43] I. Tóth-Király, B. Bőthe, A. N. Márki, A. Rigó, and G. Orosz, "Two sides of the same coin: the differentiating role of need satisfaction and frustration in passion for screen-based activities," European Journal of Social Psychology, vol. 49, pp. 1190-1205, 2019.

[44] G. S. Becker and K. M. Murphy, "A theory of rational addiction," Journal of Political Economy, vol. 96, no. 41, 1988.

[45] L. g. Pujol, "Realism in virtual reality applications for cultural heritage," International Journal of Virtual and Augmented Reality, vol. 10, pp. 41-49, 2011.

[46] R. Misra, S. Singh, and N. Singh, "Assessing behavioral patterns for online gaming addiction," International Journal of Cyber Behavior, Psychology and Learning, vol. 10, no. 2, pp. 43-64, 2020.

[47] V. A. Zeithaml, "Consumer perceptions of price, quality, and value: a means-end model and synthesis of evidence," Journal of Marketing, vol. 52, no. 3, pp. 2-22, 1988.

[48] M. J. Bitner and A. R. Hubbert, "Encounter satisfaction versus overall satisfaction versus quality: the customer's voice," in Service Quality: New Directions in Theory and PracticeSAGE Publications, Thousand Oaks, CA, USA, 2012.

[49] S. Lee, J. Park, and S. Bryan Lee, "The interplay of internet addiction and compulsive shopping behaviors," Social Behavior and Personality: An International Journal, vol. 44, no. 11, pp. 1901-1912, 2016.

[50] C. L. Hsu and M. C. Chen, "How does gamification improve user experience? An empirical investigation on the antecedences and consequences of user experience and its mediating role," Technological Forecasting and Social Change, vol. 132, pp. 118-129, 2018.

[51] M. van Gisbergen, M. Kovacs, F. Campos, M. van der Heeft, and V. Vugts, "What we don't know. the effect of realism in virtual reality on experience and behaviour," Augmented Reality and Virtual Reality, Springer, Berlin, Germany, pp. 45-57, 2019.

[52] M. Slater, "Place illusion and plausibility can lead to realistic behaviour in immersive virtual environments," Philosophical Transactions of the Royal Society B: Biological Sciences, vol. 364, no. 1535, pp. 3549-3557, 2009.

[53] A. Bandura, "Self-efficacy: toward a unifying theory of behavioral change," Advances in Behaviour Research and Therapy, vol. 1, no. 4, pp. 139-161, 1978.

[54] A. Bandura, G. V. Caprara, C. Barbaranelli, M. Gerbino, and C. Pastorelli, "Role of affective self-regulatory efficacy in diverse spheres of psychosocial functioning," Child Development, vol. 74, no. 3, pp. 769-782, 2003.

[55] L. Mallalieu and K. M. Palan, "How good A shopper Am I? Conceptualizing teenage girls ' perceived shopping competence," Academy of Marketing Science Review, vol. 2006, pp. 1-28, 2006.

[56] E. Zetou, N. Vernadakis, V. Derri, E. Bebetsos, and F. Filippou, "The effect of game for understanding on backhand tennis skill learning and self-efficacy improvement in elementary students," Procedia - Social and Behavioral Sciences, vol. 152, pp. 765-771, 2014.

[57] L. Schjoedt and J. B. Craig, "Development and validation of a unidimensional domain-specific entrepreneurial self-efficacy scale," International Journal of Entrepreneurial Behavior \& Research, vol. 23, no. 1, pp. 98-113, 2017.

[58] Y. Peng, H.-H. Hsiung, and K.-H. Chen, "The level of concern about FengShui in house purchasing: the impacts of self-efficacy, superstition, and the big five personality traits," Psychology \& Marketing, vol. 30, pp. 461-469, 2010.

[59] D. J. Ketelhut, "Assessing gaming, computer and scientific inquiry self-efficacy in a virtual environment," in Serious Educational Game Assessment, L. Annetta and S. C. Bronack, Eds., pp. 1-18, Sense Publishers, Rotterdam, Netherlands, 2011.

[60] S. F. Verkijika, "If you know what to do, will you take action to avoid mobile phishing attacks": self-efficacy, anticipated regret, and gender," Computers in Human Behavior, vol. 101, pp. 286-296, 2019.

[61] M. Dindar and Y. Akbulut, "Role of self-efficacy and social appearance anxiety on gaming motivations of MMOFPS players," Computers \& Education, vol. 81, pp. 26-34, 2015.

[62] J. M. Pina and V. Bordonaba-Juste, "Students' experience with online simulation games: from computer anxiety to satisfaction," Interacting with Computers, vol. 30, no. 2, pp. 162-171, 2018.

[63] Y. Shu, Y. Z. Huang, S. H. Chang, and M. Y. Chen, "Do virtual reality head-mounted displays make a difference? A comparison of presence and self-efficacy between head-mounted displays and desktop computer-facilitated virtual environments," Virtual Reality, vol. 23, no. 3, 2018.

[64] M. Eisenbeiss, B. Blechschmidt, K. Backhaus, and P. A. Freund, "The (real) world is not enough:" motivational drivers and user behavior in virtual worlds," Journal of Interactive Marketing, vol. 26, no. 1, pp. 4-20, 2012.

[65] I. Bogost, Persausive Games: The Expressive Power of Video Games, MIT Press, Cambridge, MA, USA, 2007.

[66] J. Juul, “Games telling stories?" International Journal of Computing, vol. 1, 2001.

[67] R. W. Belk, "Extended self in a digital world: table 1," Journal of Consumer Research, vol. 40, no. 3, pp. 477-500, 2013.

[68] D. Murphy, "Virtual reality is "finally here": a qualitative exploration of formal determinants of player experience in VR," in Proceedings of the 2017 DiGRA International Conference, Melbourne, Australia, July 2017.

[69] D. J. Chalmers, "The virtual and the real," Disputatio, vol. 9, pp. 309-352, 2017.

[70] J. Robson and G. Tavinor, "Videogames and virtual media," in The Aesthetics of Videogames, pp. 146-160, Routledge, Abingdon, UK, 2018.

[71] R. Lavoie, K. Main, C. King, and D. King, "Virtual experience, real consequences: the potential negative emotional consequences of virtual reality gameplay," Virtual Reality, 2020.

[72] R. L. Oliver, "A cognitive model of the antecedents and consequences of satisfaction decisions," Journal of Marketing Research, vol. 17, no. 4, pp. 460-469, 1980.

[73] J. M. Vervoort, "New frontiers in futures games: leveraging game sector developments," Futures, vol. 105, pp. 174-186, 2018.

[74] T. Waltemate, D. Gall, D. Roth, M. Botsch, and M. E. Latoschik, "The impact of avatar personalization and immersion on virtual body ownership, presence, and emotional response," IEEE Transactions on Visualization and Computer Graphics, vol. 24, no. 4, pp. 1643-1652, 2018.

[75] H. P. Lu and S. m. Wang, "The role of Internet addiction in online game loyalty: an exploratory study," Internet Research, vol. 18, no. 5, pp. 499-519, 2008. 
[76] D. H. hin, "The role of affordance in the experience of virtual reality learning: technological and affective affordances in virtual reality," Telematics and Informatics, vol. 34, no. 8, pp. 1826-1836, 2017.

[77] S. B. Nelson, M. H. Jarrahi, and L. Thomson, "Mobility of knowledge work and affordances of digital technologies," International Journal of Information Management, vol. 37, no. 2, pp. 54-62, 2017.

[78] S. T. Tokel and V. İsler, "Acceptance of virtual worlds as learning space," Innovations in Education and Teaching International, vol. 52, no. 3, pp. 254-264, 2015.

[79] G. Makransky and G. B. Petersen, "Investigating the process of learning with desktop virtual reality: a structural equation modeling approach," Computers \& Education, vol. 134, pp. 15-30, 2019.

[80] D. Kim and Y. J. Ko, "The impact of virtual reality (VR) technology on sport spectators' flow experience and satisfaction," Computers in Human Behavior, vol. 93, pp. 346-356, 2019.

[81] W. Ribbens, S. Malliet, R. Van Eck, and D. Larkin, "Perceived realism in shooting games: towards scale validation," Computers in Human Behavior, vol. 64, pp. 308-318, 2016.

[82] M. Kim, M. Park, J. Park et al., "The role of multidimensional switching barriers on the cognitive and affective satisfactionloyalty link in mobile communication services: coupling in moderating effects," Computers in Human Behavior, vol. 87, 2018.

[83] M. Gong, L. Yu, and A. Luqman, "Understanding the formation mechanism of mobile social networking site addiction: evidence from WeChat users," Behaviour \& Information Technology, vol. 0, pp. 1-16, 2019.

[84] K. T. Manis and D. Choi, "The virtual reality hardware acceptance model (VR-HAM): extending and individuating the technology acceptance model (TAM) for virtual reality hardware," Journal of Business Research, vol. 100, pp. 503-513, 2019.

[85] C. Fornell and D. F. Larcker, "Structural equation models with unobservable variables and measurement error: algebra and statistics," Journal of Marketing Research, vol. 18, no. 3, 1981.

[86] J. F. Hair, W. C. Black, B. J. Babin, and R. E. Anderson, Multivariate Data Analysis, Pearson Education, Upper Saddle River, NJ, USA, 7th edition, 2014

[87] P. M. Podsakoff, S. B. MacKenzie, and N. P. Podsakoff, "Common method biases in behavioral research: a critical review of the literature and recommended remedies," Journal of Applied Psychology, vol. 88, no. 5, p. 879, 2003.

[88] L. t. Hu and P. M. Bentler, "Cutoff criteria for fit indexes in covariance structure analysis: conventional criteria versus new alternatives," Structural Equation Modeling: A Multidisciplinary Journal, vol. 6, no. 1, pp. 1-55, 1999.

[89] K. J. Preacher and A. F. Hayes, "Asymptotic and resampling strategies for assessing and comparing indirect effects in multiple mediator models," Behavior Research Methods, vol. 40, no. 3, 2008.

[90] G. Crawford, D. Muriel, and S. Conway, "A feel for the game: exploring gaming 'experience' through the case of sportsthemed video games," Convergence, vol. 25, no. 5-6, pp. 937-952, 2019.

[91] J.-H. T. Lin, D.-Y. Wu, and C.-C. Tao, "So scary, yet so fun: the role of self-efficacy in enjoyment of a virtual reality horror game," New Media \& Society, vol. 20, no. 9, pp. 3223-3242, 2018.

[92] P. Dullur and P. Hay, "Problem internet use and internet gaming disorder: a survey of health literacy among psychiatrists from Australia and New Zealand," Australasian Psychiatry, vol. 25, pp. 140-145, 2017.

[93] J. Gackenbach, D. Wijeyaratnam, and C. Flockhart, The Video Gaming Frontier, Elsevier, Amsterdam, Netherlands, 2017.

[94] C. L. Huang, Y. F. Luo, S. C. Yang, C. M. Lu, and A.-S. Chen, "Influence of students' learning style, sense of presence, and cognitive load on learning outcomes in an immersive virtual reality learning environment," Journal of Educational Computing Research, vol. 58, no. 3, 2019.

[95] M. D. Griffiths, D. J. Kuss, and D. L. King, "Video game addiction: past, present and future," Current Psychiatry Reviews, vol. 8, no. 4, 2012. 